\title{
Patrick W. Nye
}

\section{6-2008}

Patrick W. Nye, most of whose professional career was spent at Haskins Laboratories, died at the age of 71 March 7, 2008 as the result of a heart stoppage suffered while riding his bicycle to the post office in Port Ludlow, Wash., USA a few days earlier.

Pat's value to the Laboratories was multifaceted. He served as Research Scientist 1971-1975, Associate Director of Research

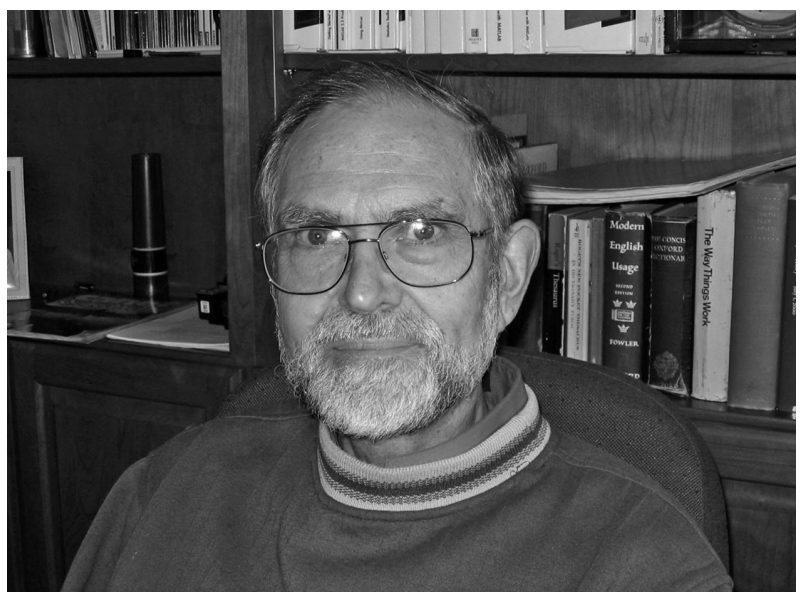
1975-1992, Vice President

for Administration 1992-1997, Member of the Board of Directors 1996-2007, and Chairman of the Board 2002-2006. One of his accomplishments is the compiling of a valuable oral history of Haskins Laboratories. Another is the careful preparation of a handbook for the role of graduate research assistants at the Laboratories during a period of somewhat hectic transition from New York City to rather different circumstances in New Haven. Even when carrying heavy administrative responsibilities he did not neglect his involvement in speech research.

Pat was born April 19, 1936 to Frederick and Eurica Nye in Yeovil, Somerset, England. He spent his early life growing up in Somerset. He took his BSc degree in physics in 1958 and the PhD in physics in 1962, both at Reading University, Reading, England. He married Elaine Lyon July 4, 1958.

It was Pat's work on reading machines and related topics that led to his being invited to join the staff of Haskins Laboratories [e.g. Nye, 1962, 1963]. He also made important contributions in the development of the Haskins articulatory synthesizer [e.g. Cooper et al., 1977; Abramson et al., 1981]. Over the past few years his research work has focused on shadowing and imitation with Carol A. Fowler [Nye and Fowler, 2003]

\begin{tabular}{ll}
\hline KARGER & @ 2009 S. Karger AG, Basel \\
O0031-8388/08/0654-0270 \\
Fax +4161306 12 34 & $\$ 24.50 / 0$ \\
E-Mail karger@ karger.ch & Accessible online at: \\
www.karger.com & www.karger.com/pho
\end{tabular}


and the acoustics of the production and perception of voice registers in Mon-Khmer languages with me [e.g. Abramson et al., 2007].

Pat is survived by his wife Elaine, their children Adrian and Philippa, a brother Roger, and a sister Cynthia. If I may inject a personal note, let me say that I have lost an excellent colleague in both scientific and administrative matters and a dear friend.

Arthur S. Abramson, New Haven, Conn., USA

\section{References}

Abramson, A.S.; Nye, P.W.; Henderson, J.B.; Marshall, C.W.: Vowel height and the perception of consonantal nasality. J. acoust. Soc. Am. 70: 329-339 (1981).

Abramson, A.S.; Nye, P.W.; Luangthongkum, T.: Voice register In Khmu': experiments in production and perception. Phonetica 64: 80-104 (2007).

Cooper, F.S.; Mermelstein, P.; Nye, P.W.: Speech synthesis as a tool for the study of speech production; in Sawashima, Cooper, Dynamic aspects of speech production, pp. 307-322 (University of Tokyo Press, Tokyo 1977).

Nye, P.W.: Aural recognition time for multi-dimensional signals. Nature 196: 1282 (1962).

Nye, P.W.: Psychological factors limiting the rate of acceptance of audio stimuli; in Clark, Technology and blindness, pp. 99-109 (American Foundation for the Blind, New York 1963).

Nye, P.W.; Fowler, C.A.: Shadowing latency and imitation: the effect of familiarity with the phonetic patterning of English. J. Phonet. 31: 63-79 (2003). 